\title{
Evaluation of Integrity of Mesh of Different Orthodontic Brackets
}

Omar H Alluazy

BDS, MSc (Asst Lec.)

\author{
Dept of Pedod, Orthod and Prev Dentistry \\ College of Dentistry, University of Mosul
}

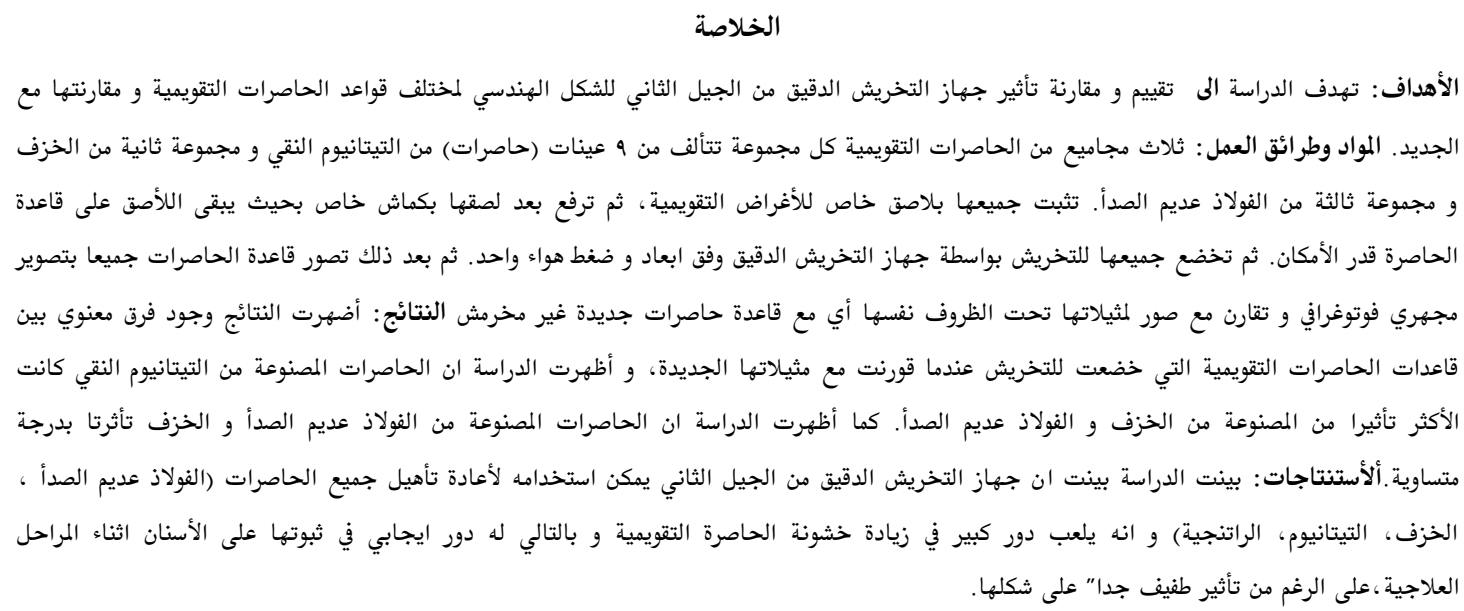

ABSTRACT

Aims: To evaluate and compare the effect of micro etcher model II on geometrical integrity of base of variable types of orthodontic brackets after etching and compared with new bracket. Materials and Methods: Twenty seven brackets were divided into three groups of nine. Group one was titanium brackets, group two was stainless steel brackets and group three was ceramic brackets. Brackets had been previously bonded to glass slide with same adhesives. All groups were carefully removed with debonding plier and again all groups cleaned from the adhesive material by microetcher and the bases of all brackets examined with stereomicroscope and compared with control group. Results: There are significant differences between the control group and reconditioning groups "stainless steel, pure titanium and ceramic brackets". While, the stainless steel and ceramic groups have the lower percentage of deformity in geometrical integrity. Also, the reconditioned groups showed no significant difference among them.Conclusions: This study showed that the microetcher can be used for reconditioning for all types of orthodontic bracket bases; however, minimal damaging may be occurring in orthodontic bracket. Microetcher plays a role in roughness of base of orthodontic bracket.

Key words: Microetcher, mesh, recycling, bracket, ceramic.

Alluazy OH, Evaluation of Integrity of Mesh of Different Orthodontic Brackets. Al-Rafidain Dent J. 2011; 11(2): 364-369.

Received: $20 / 4 / 2010$

Sent to Referees: $22 / 4 / 2010$

Accepted for Publication: 27 /7/2010

\section{INTRODUCTION}

To enhance the retention of the adhesive to the metal base of orthodontic brackets, various chemical and mechanical retentive design have been suggested . Mechanical retention was enhanced by placing undercuts in the cast bracket bases or by welding different diameter mesh wires to the bracket base as well as incorporating different designs in the mesh itself. Other innovative approaches to improve retention included using laserstructured bases, using metal plasmacoated bracket bases and fusing metalic or ceramic particles to the bases. One of the major challenges associated with the use of bracket for orthodontic treatment is the accidental dislodgement of an orthodontic bracket due to occlusal trauma or intentional removal of bracket in order to reposit it to achieve ideal occlusal goals. It is necessary either to rebond the dislodged bracket or to bond a new one. ${ }^{(1)}$

The orthodontic clinician requires a reliable method of attachment to tooth tissue. ${ }^{(2)}$ The method of attachment must allow the delivery of orthodontic forces and must be sufficiently robust to withstand 
masticatory loads. In addition, the attachment must be aesthetic, easily removed at the end of treatment and result in minimal hard and soft tissue damage during application. The undercut in most metal bracket is provided by a brazed fine mesh. ${ }^{(3)}$ However, other bracket bases carry milled undercut or sintered with porous metal powder. It has been also used to improve the bond strength of reconditioned brackets by use high - speed stream of aluminum oxide particles propelled by compressed air to remove old adhesive parts from the base of the accidentally debond bracket for increase surface roughness. ${ }^{(4)}$

Bracket base morphology can influence the retention of bracket base, this is called geometry (depth, size). ${ }^{(5)}$ The purpose of this in vitro study was to evaluate and compare the effect of micro etcher model II on geometrical integrity of base of variable types of orthodontic brackets after cleaning them and compared with new bracket.

\section{MATERIALS AND METHODS}

This study test sample is composed of twenty seven brackets divided into three groups: nine pure titanium bracket roth design "0.018x0.030" bicuspid with casted integral base Rematition (Dentaurum, Germany), nine stanless steel standard edge wise "0.018x0.030" with single layer mesh "foil mesh" Ultra - minitrim (Dentaurum, Germany), and nine ceramic brackets "0.018x0.030" with retentive elongated groove (Dentaurum, Germany)

A photographed view at $20 \mathrm{X}$ magnification was taken for integral base of pure titanium, foil mesh of stainless steel and groove of base of ceramic bracket and views were taken for bracket by stereomicroscope and digital camera. ${ }^{(6)}$

\section{Methods:}

Step One:The three bracket groups were bonded on glass slide by following both glass slide and bracket base were coated with a thin layer of orthodontic composite (Biofix orthodontic adhesive), then positioned on glass slide and seated under standard force 500g. ${ }^{(7)}$ Excess resin flash around the base was removed with dental explorer. ${ }^{(8)}$ Light was then applied for 10 seconds on proximal side to cure adhesive then bracket debonded by using plier after one hour in way by which the resin remain intact on base of bracket with crack or fragment of cured composite. ${ }^{(8)}$

Step Two: Cleaning of the debonded brackets: by using microetcher model II (Danville Engineering and Material, USA), it consists of micro handpiece air line and nozzle and hold by the tip of nozzle $3 \mathrm{~mm}$ away from the bracket base and the tip of nozzle move mesiodistal direction sweep method by using a holder designed make the nozzle move for $6 \mathrm{~mm}$ mesiodistal direction and the base of each debonded bracket was etched at 65 PSI 30 seconds with aluminum oxide 50 micron particle size. ${ }^{(9)}$

Then the brackets of three groups wire view under microscope at magnification 20X. ${ }^{(10)}$ and photographs were taken for all the brackets at constant quality, fine and high resolution of digital camera. ${ }^{(11)}$ as in figure(1) To determine how much residual adhesive remained on the mesh according to the following scale: $1=$ all the composite remained on the tooth, $2=$ more than $90 \%$ of the composite remained on the tooth, $3=$ more than $10 \%$ but less than $90 \%$ remained on the tooth, $4=$ less than $10 \%$ remained on the tooth, and $5=$ no composite remained on the tooth. ${ }^{(12)}$ The higher thepercentage of the open area, the better result. ${ }^{(13-17)}$

\section{RESULTS}

The descriptive analysis (minimum, maximum, mean and SD) for the four groups are listed in Table (1).The findings of this study showed the mean of the control group gave rise to the highest percentage of damaging of geometrical integrity followed by ceramic group then stainless steel group, while the pure titanium group showed the lowest value when compared with remaining groups, as in Table (2) and Figure (2). The analysis of variance (ANOVA) for the four groups showed significant difference $(p<0.001)$ among them as in the Table (3). The control group, pure titanium, stainless steel and ceramic groups showed significant difference $(p \leq 0.05)$, while the stainless steel and ceramic group showed no significant difference $(p>0.05)$ Table (4). 


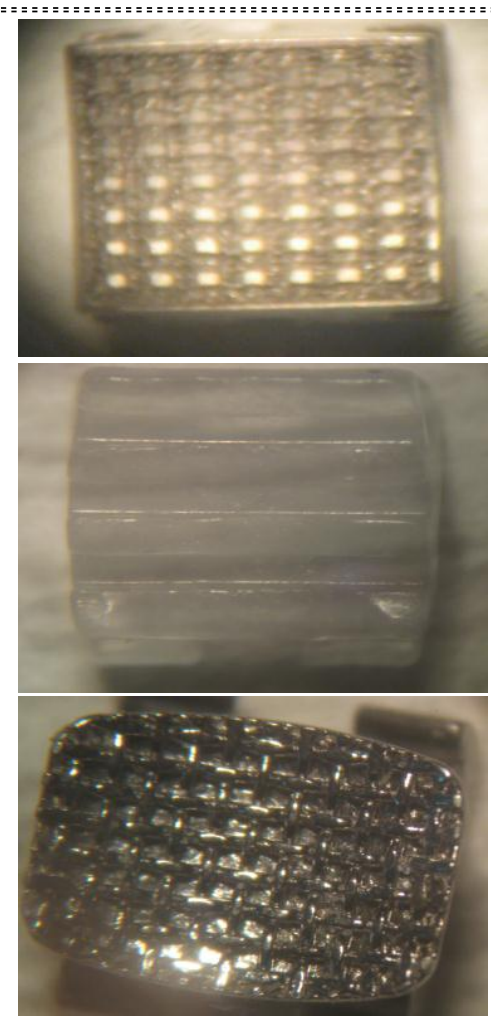

Before
Titanium Bracket

Ceramic Bracket

Stainless steel Bracket
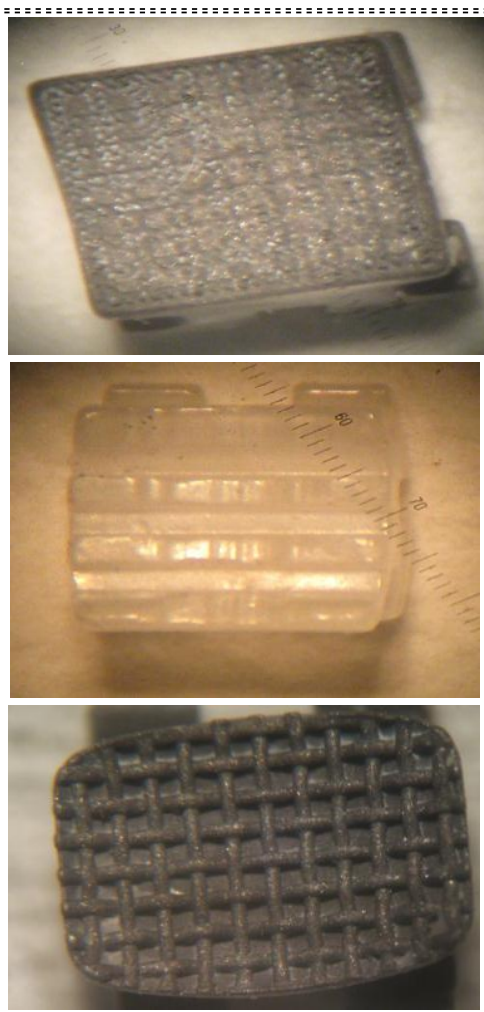

After

Figure (1) Different orthodontic bracket base before and after etching under stereo microscope

Table (1): The descriptive statistics of the effect of microetcher on bases of variable orthodontic brackets.

\begin{tabular}{ccccccc}
\hline Groups & No. & Minimum & Maximum & $\begin{array}{c}\text { Mean } \\
(\boldsymbol{\%})\end{array}$ & $\begin{array}{c}\text { Standard devia- } \\
\text { tion }\end{array}$ & $\begin{array}{c}\text { Standard } \\
\text { error }\end{array}$ \\
\hline $\begin{array}{c}\text { Control } \\
\text { Pure titani- }\end{array}$ & 9 & 1.00 & 0.1 & 1.000 & 0.000 & 0.000 \\
$\begin{array}{c}\text { um } \\
\text { Stainless } \\
\text { steel }\end{array}$ & 9 & 0.94 & 0.99 & 0.963 & 0.015 & 0.005 \\
Ceramic & 9 & 0.98 & 0.99 & 0.985 & 0.005 & 0.001 \\
\hline
\end{tabular}

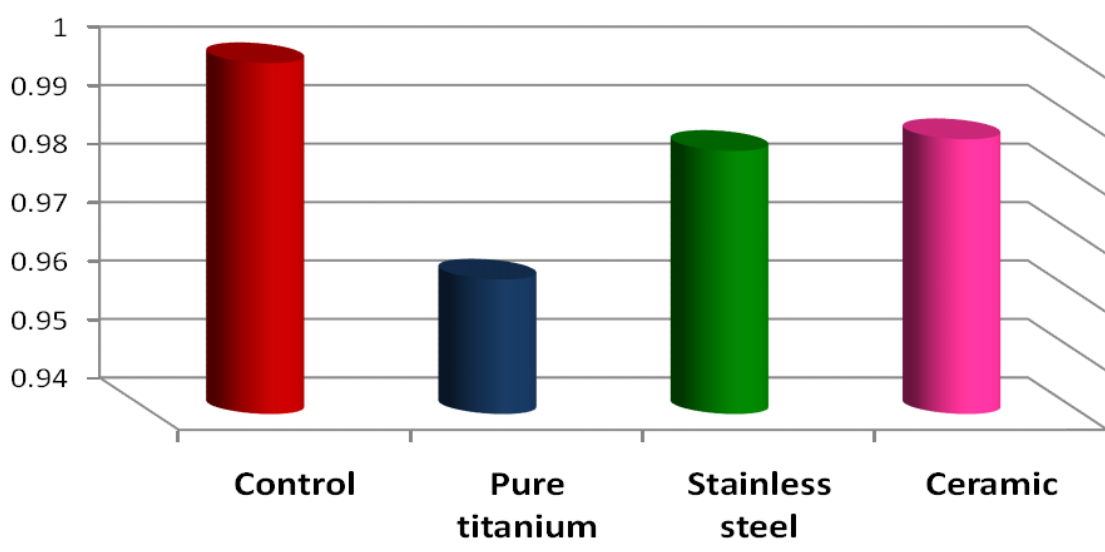

Figure (2): Comparison demonstrated the effect of micro-etcher on bases of variable orthodontic brackets. 
Table (2): $\mathrm{T}$ - test comparison of the effect of micro-etcher among groups of bracket

\begin{tabular}{ccccc}
\hline Groups & Mean $(\%) \pm$ SD & T - value & $p$-value & Sig. \\
\hline Control & $1.00 \pm 0.000$ & 7.333 & 0.000 & S \\
Pure titanium & $0.96 \pm 0.015$ & & & \\
$\quad$ Control & $1.00 \pm 0.000$ & 8.222 & 0.000 & S \\
$\begin{array}{c}\text { Stainless steel } \\
\text { Control } \\
\text { Ceramic }\end{array}$ & $0.98 \pm 0.005$ & 8.315 & 0.000 & $\mathbf{S}$ \\
\hline
\end{tabular}

S: Significant difference at $p \leq 0.05$

Table (3): The analysis of variance (ANOVA) among bracket groups for determining the effect of microetcher on variable base of brackets for the four groups

\begin{tabular}{cccccc}
\hline & Sum of Square & df & Mean Square & F- value & $\boldsymbol{P}$ \\
\hline Between groups & 0.006 & 3 & 0.002 & & \\
Within groups & 0.002 & 32 & 0.000 & 30.844 & $<0.001$ \\
Total & 0.008 & 35 & & & \\
\hline
\end{tabular}

Different letters mean significant difference at $p \leq 0.05$

Table (4): Duncan's multiple range test among bracket groups for determining the effect of microetcher on variable base of brackets for the four groups.

\begin{tabular}{lllll}
\hline Groups & No. & Mean $(\%)$ & Standard error & Duncan's group \\
\hline $\begin{array}{l}\text { Control } \\
\text { Pure titani- }\end{array}$ & 9 & 1.000 & 0.000 & $\mathrm{~A}$ \\
um & 9 & 0.963 & 0.005 & $\mathrm{~B}$ \\
$\begin{array}{l}\text { Stainless } \\
\text { steel }\end{array}$ & 9 & 0.985 & 0.001 & $\mathrm{C}$ \\
Ceramic & 9 & 0.987 & 0.001 & $\mathrm{C}$ \\
\hline Different letters mean significant difference at $p \leq 0.05$ &
\end{tabular}

Different letters mean significant difference at $p \leq 0.05$

\section{DISCUSSION}

Aluminum - oxide blasting technique was originally intended to enhance the mechanical retention of new and debonded brackets as well as to prepare enamel surface. Aluminum oxide air - abrasion has been proved a good option for reconditioning of orthodontic bracket, easy technique can be performed in dental office, gave good benefit from the economic view and time consuming.

The result of this study showed statistically difference between the new and etched brackets, this result is in agreement with Basudan and $\mathrm{Al}$ - Emran, Mete and Selim). ${ }^{(7,18)}$ This finding is clearly due to the facts that the $\mathrm{Al}_{2} \mathrm{O}_{3}$ sandblasting of bracket base creates an effective micro - roughened surface on the bracket base, which increase the area for bonding adhesive in comparison to the new bracket, however, causing very minimal damaging for geometry of bracket base.

The present finding also differ from those of Stenyo et al. ${ }^{(19)}$ and Seema et al. ${ }^{(20)}$ who found that there is no statistically significant difference between the geometry of the base of new bracket and etched brackets.

The finding of this study disagrees with Sunna and Rock. ${ }^{(21)}$ who found no significant difference between conditioned or etched and new bracket, while this study agree with Oonsombat et al. ${ }^{(22)}$, Bishara et al. ${ }^{(12)}$ and Wheeler et al. ${ }^{(23)}$ who all found a significant difference between new and sandblasted brackets.

\section{CONCLUSIONS}

This investigation revealed that the micro - etcher can be used for recondi- 
tioning of all types of orthodontic bracket base. However, minimal damaging may be occurring on orthodontic bracket base as loss of luster especially when stainless steel bracket, where etched and more time consuming need. The more complex base design was etched as double mesh soldered in stainless steel bracket. While, less time consuming when ceramic bracket was used because it has elongated retentive groove only.

\section{REFERENCES}

1. Mui B, Rossouw PE, Kullkarni GV. Optimization of a procedure for rebonding dislodged orthodontic brackets. Angle Orthodont. 1999; 64(3):276 - 281.

2. Jeremy Knox, Pierre Hubsch, Malcolm L Jones, John Middleton. The influence of bracket base design on the strength of bracket - cement interface. $\mathrm{Br} J$ orthod 2000;27(3)249-254

3. Hanson GH, Gibbon WM, Shimuzu H. Bonding bases coated with porous metal powders. Am J Orthodont. 1983; 83: 1 -4.

4. Pinido SMMO, Mortins JCR, Santos Pinto A, Sakima MT. A valiacao resistencia cisalha mento de brquetes reciclados e novos recolados. Rev Dent Press Orthodo Orthopedi Facial. 1998; 3: 45 - 52.

5. Tavares SW, Consani S, Nouer DF, Magnani MBBA, Pereira JS Neto. Evaluation in vitro of shear bond strength of aluminum oxide recycled bracket. Braz $J$ Oral Sci. 2003; 2: 378 - 381.

6. Seema K, Sharma - Sayal, P Emil Rossauw, Gajanan V Kulkarni, Keith G Tittey. The influence of orthodontic bracket base design on shear bond strength. Am J Orthod Dentofac Orthop. 2003; 124: 74 82.

7. Basudan $\mathrm{AM}$ and $\mathrm{Al}-$ Emran SE. The effect of in - office reconditioning on the morphology of slots and bases of stainless steel brackets on the shear / peel bond strength. Bri J Orthod. 2001; 28(3): 231 236.

8. Theodorakopoulou LP, Sadowsky PH, Jacobson A, Lacefield W. Evaluation of the debonding characteristics of two ceramic brackets: an in vitro study. $A m J$ Orthod Dentofac Orthop. 2004; 125(3): $329-336$.

9. Mathus Melo Pithon, Marlio Vinicius de Oliveira, Antonio Carlos de Oliverira Ru- ellas, Ana Maria Bolognese, Fabio Lourenco Romano. Shear bond strength of orthodontic brackets to enamel under different surface treatment conditions. J Appl Oral Sci. 2007; 15(2): 127 - 130.

10. Spiros Zinelis, Olga Annonsaki, Margarita Makou and Theodore Eliades. Metallurgical characterization of orthodontic brackets produced by metal injection molding. Angle Orthodont .2005; 75(6);1024-1031

11. Rodney G, Norhru P, David W. Beizins, Thomas Gerard Bradley, William Schuckit. Shear bond strength comparison between two orthodontic adhesives and self - lighting and conventional bracket. Angle Orthodont. 2007; 77(4): 701 - 706.

12. Samir E Bishara, Manal MA Soliman, Charuphan Oonsombat, John Filaffon, Raed Ajlouni. The effect of variation in mesh - base design on the shear bond strength of orthodontic bracket.Angle Orthodont.2004;74(3):400-404

13. Sorel O, El - Alam R, Chagnedy F, Gathelineau G. Comparison of bond strength between simple foil and laser structured base retention brackets. Am J Orthod Dentofac Orthop. 2002; 122: 260 $-266$.

14. Droese V and Diedrich P. The tensile bonding strength of metal plasma - coated bracket bases. Fortschrkufer Orthop. 1992; 53: $142-152$.

15. White $\mathrm{J}$ and Eakle W. Rational and treatment approach in minimally invasive dentistry. J Am Dent Assoc. 2000; 131(1): $13 \mathrm{~S}-19 \mathrm{~S}$.

16. Matasa CG. Do adhesives and sealants really seal the bracket pad? Surface tension. The Orthodont Mater Insider. 2003; 15: $4-10$.

17. Wang WN, LiCH, Chou TH, Wang DD, Lin LH, Lin CT. Bond strength of various bracket base designs. AMJ Orthod Dentofac Orthop , 2004; 125 : 65-70.

18. Mete $O$ and Selim A. Sandblasted metal brackets bonded with resin - modified glass. Angle Orthodont. 2005; 75(3): 406 409.

19. Stenyo W, Simonides C, Darcy F. Shear bond strength of new and recycled brackets to enamel. Braz Dent J. 2006; 17(1): $44-48$.

20. Seema K, Rossow P, Gajanan V, Keith C. The influence of orthodontic bracket base design on shear bond strength. Am J Or- 
thod Dentofac Orthop. 2003; 124(1): 74 82.

21. Sunna S and Rock WP. Effect of sandblasting on the retention of orthodontic brackets: a controlled clinical trail. J Orthodont. 2008; 35(1): $43-48$.

22. Oosombat C, Laffoon JF, Soliman MMT, Bishara SE. The effect of variation in mesh - base design on the shear bond strength of the orthodontic brackets. Angle Orthodont. 2004; 74(3): 400 - 404.

23. James J. Wheeler and Richard J. Ackerman. Bond strength of thermally recycled metal brackets. Am J Orthod Dentofac Orthop. 1998; 1983: $181-186$. 